\title{
Anesthetic Potency of Ketamine in Caspian Terrapin, Freshwater Soft Shell Tortoise and Rat Snake Collected from Bahar Al Najaf District, Al-Najaf Province
}

\author{
Ayad N.D. Alhakim \\ Lectural, University of Kufa, Faculty of Veterinary Medicine, Kufa, Iraq
}

\begin{abstract}
The study was carried out during April 2012. Twelve Caspian terrapins,twelve freshwater soft-shell turtles and 6 rat snakes were collected from Baher Al-Najaf by professional reptiles collectors from Al-Rafidin association for hunting and environment protection, the present study include 3 separated experiments. The terrapins placed in 6 glass aquariums (couple per aquariums) the maintenance conditions controlled after adaptation for one week, all terrapins distributed equally into 3 groups. The animals of group 1, 2 and 3 were injected intramuscularly with 40,60 and $80 \mathrm{mg}$ ketamine. The anesthetic levels were assessed. Freshwater soft-shell turtles experiment, this experiment was same to previous experiment. The rat snakes placed in 2 plastic containers distributed into 2 groups, the maintenance conditions. The snake of 1.2-and3 group were injected with 40, 60 and $80 \mathrm{mg} / \mathrm{kg}$ intramuscularly. The anesthetic levels were assessed. We note in Table 1 that when ketamine was injected at a dose of 40,60 and $80 \mathrm{mg} / \mathrm{kg}$ of body weight, the minimum onset time for doses was $(15,7,5)$, while the most time was $(17,10,5)$ respectively. While we noticed the minimum a loss of the right reflex, deep anesthesia, recovery right reflex and completed recovery was $(21,12,8)$, $(47,58,76),(87,120,140)$ and $(18,24,64)$. We note in Table 3 that when ketamine was injected at a dose of 40,60 and $80 \mathrm{mg} / \mathrm{kg}$ of body weight, the minimum onset time for doses was $(4,4,3)$, while the most time was $(12,5,5)$ respectively. While we noticed the minimum a loss of the right reflex, deep anesthesia, recovery right reflex and completed recovery was $(8,4,5),(50,40,74),(290,260,290)$ and $(62,70,70)$.Therefore, the best dose is $80 \mathrm{mg} / \mathrm{kg}$ for Caspian terrapin, while for freshwater soft shell tortoise it is $80 \mathrm{mg} / \mathrm{kg}$. As for rat snake, the ketamine dose of $80 \mathrm{mg} / \mathrm{kg}$ of body weight was the best according to the study.
\end{abstract}

Keywords: Anesthetic potency, Caspian terrapin, Rat Snake, Bahar Al Najaf district etc.

\section{Introduction}

The necessity of researches about reptile's medicine and surgery has being increasing in recent years, either due to considering reptiles as pet animals or for conservation point ${ }^{(1)}$. The reptiles are difficult to handling and the chemical restrain are necessary to clinical examination, minor surgical operation and biometry recording ${ }^{(2)}$. Ketamine was originally

\footnotetext{
Corresponding Author:

Ayad N.D. Alhakim

Lectural, University of Kufa, Faculty of Veterinary

Medicine, Kufa, Iraq

e-mail: ayadn.dheyaa@uokufa.edu.iq
}

developed for human use as cheap,injectable and safe anesthetic,these advantages were formed a ketamine to use in all primates,many zoological and exotic animals, and in birds and reptiles ${ }^{(3)}$. Mostly,there are no anesthetic has been approved to use in reptiles in addition to variable anesthetic effects between individuals of the same species have been observed in reptile anesthesia studies and have been anecdotally attributed to possible differences in temperature, body size, body condition, sex, stress level, administration route and elapsed time since previous dosing ${ }^{(10)}$. For these reasons the present study was designed to determined the anesthetic effect of ketamine in variant dose scale in three reptiles species including Caspian terrapin (Mauremys caspica), freshwater soft shell turtle (Rafetus euphraticus) and rat snake (Colubridae reptilia) collected from Bahar AlNajaf district-Al- Najaf province/Iraq. 


\section{Materials and Method}

Collection and maintenance of reptiles: The study was carried out during April 2012. Twelve Caspian terrapins, 12 freshwater soft-shell turtles and 6 rat snakes were collected from Baher Al-Najaf by professional reptiles collectors from Al-Rafidin association for hunting and environment protection, the present study include 3 separated experiments as followings:

Caspian terrapin experiment: The terrapins placed in 6 glass aquariums (couple per aquariums) the maintenance conditions controlled according to ${ }^{(7)}$. After adaptation for one week, all terrapins distributed equally into 3 groups. The animals of group 1, 2 and 3 were injected intramuscularly ${ }^{(8)}$ with 40,60 and 80 mg ketamine ${ }^{(5)}$. The anesthetic levels were assessed according ${ }^{(8)}$.

Freshwater soft-shell turtles experiment: This experiment was same to previous experiment. Rat snake experiment: The rat snakes placed in 2 plastic containers distributed into 2 groups, the maintenance conditions ${ }^{(7)}$ approved according to ${ }^{(12,17)}$. The snake of 1.2 and 3 group were injected with 40,60 and $80 \mathrm{mg} /$ $\mathrm{kg}$ intramuscularlyin table 3 . The anesthetic levels were assessed according ${ }^{(11)}$. All reptiles were released in their natural habit after 2 weeks of experiments.

\section{Results}

Table 1: Onset of anesthesia and recovery time induced by the anesthetic agents (ketamine) in 12 Caspian terrapin (mean \pm standard deviation)

\begin{tabular}{|c|c|c|c|c|c|}
\hline Dose $\mathbf{~ m g / k g ~ b ~ w ~}$ & $\begin{array}{c}\text { Time of onset } \\
(\mathbf{m i n})\end{array}$ & $\begin{array}{c}\text { Loss Right reflex } \\
(\mathbf{m i n})\end{array}$ & $\begin{array}{c}\text { Deep Anesthesia } \\
(\mathbf{m i n})\end{array}$ & $\begin{array}{c}\text { Recovery right } \\
\text { reflex (min) }\end{array}$ & $\begin{array}{c}\text { Completed } \\
\text { Recovery (min) }\end{array}$ \\
\hline 40 & 17 & 22 & 48 & 90 & 22 \\
\hline 40 & 16 & 25 & 47 & 87 & 18 \\
\hline 40 & 15 & 32 & 55 & 98 & 21 \\
\hline 40 & 16 & 21 & 51 & 95 & 22 \\
\hline Mean & 16 & 25 & 50.25 & 92.5 & 20.75 \\
\hline 60 & 10 & 22 & 60 & 120 & 24 \\
\hline 60 & 10 & 15 & 58 & 155 & 27 \\
\hline 60 & 7 & 14 & 64 & 130 & 28 \\
\hline 60 & 11 & 12 & 60 & 142 & 29 \\
\hline Mean & 9.5 & 15.7 & 60.5 & 136.7 & 27 \\
\hline 80 & 5 & 8 & 77 & 150 & 67 \\
\hline 80 & 4 & 10 & 76 & 140 & 80 \\
\hline 80 & 5 & 7 & 91 & 155 & 64 \\
\hline 80 & 5 & 8 & 98 & 145 & 64 \\
\hline Mean & 4.75 & 8.25 & 85.5 & 147.5 & 69.7 \\
\hline
\end{tabular}

We note in Table 1 that when ketamine was injected 40,60 and $80 \mathrm{mg} / \mathrm{kg}$ of body weight, the minimum onset time for doses was $(15,7,5)$, while the most time was $(17,10,5)$ respectively. While we noticed the minimum a loss of the right reflex, deep anesthesia, recovery right reflex and completed recovery was $(21,12,8),(47,58,76)$, $(87,120,140)$ and $(18,24,64)$.
We note in Table 2 that when ketamine was injected 40,60 and $80 \mathrm{mg} / \mathrm{kg}$ of body weight, the minimum onset time for doses was $(12,8,6)$, while the most time was $(16,11,8)$ respectively. While we noticed the minimum a loss of the right reflex, deep anesthesia, recovery right reflex and completed recovery was $(22,18,13)$, $(43,65,74),(95,132,134)$ and $(18,30,55)$. 
Table 2 Onset of anesthesia and recovery time induced by the anesthetic agent (ketamine) in 12 freshwater soft shell turtles (Mean \pm standard deviation)

\begin{tabular}{|c|c|c|c|c|c|}
\hline $\begin{array}{c}\text { Dose mg/kg } \\
\text { b w }\end{array}$ & $\begin{array}{c}\text { Time of onset } \\
\text { (min) }\end{array}$ & $\begin{array}{l}\text { Loss Right reflex } \\
\text { (min) }\end{array}$ & $\begin{array}{c}\text { Deep Anesthesia } \\
\text { (min) }\end{array}$ & $\begin{array}{l}\text { Recovery right } \\
\text { reflex (min) }\end{array}$ & $\begin{array}{c}\text { Completed } \\
\text { Recovery (min) }\end{array}$ \\
\hline 40 & 12 & 22 & 44 & 92 & 18 \\
\hline 40 & 10 & 28 & 48 & 102 & 20 \\
\hline 40 & 14 & 32 & 55 & 98 & 25 \\
\hline 40 & 16 & 25 & 43 & 95 & 20 \\
\hline Mean & 13 & 26.75 & 47.5 & 96.75 & 20.75 \\
\hline 60 & 8 & 18 & 65 & 140 & 28 \\
\hline 60 & 10 & 21 & 74 & 142 & 32 \\
\hline 60 & 11 & 20 & 70 & 132 & 34 \\
\hline 60 & 10 & 20 & 76 & 138 & 30 \\
\hline Mean & 9.75 & 19.75 & 71.25 & 138 & 31 \\
\hline 80 & 6 & 19 & 78 & 170 & 55 \\
\hline 80 & 6 & 13 & 74 & 154 & 64 \\
\hline 80 & 8 & 15 & 76 & 134 & 62 \\
\hline 80 & 7 & 13 & 75 & 158 & 60 \\
\hline Mean & 6.75 & 15 & 75.75 & 154 & 60.25 \\
\hline
\end{tabular}

Table 3 Onset of anesthesia and recovery time induced by the anesthetic agents (ketamine) in 6 rat Snakes (mean \pm standard deviation)

\begin{tabular}{|c|c|c|c|c|c|}
\hline Dosemg/kg b w & $\begin{array}{l}\text { Time of onset } \\
\text { (min) }\end{array}$ & $\begin{array}{l}\text { Loss Right reflex } \\
\text { (min) }\end{array}$ & $\begin{array}{c}\text { Deep Anesthesia } \\
\text { (min) }\end{array}$ & $\begin{array}{l}\text { Recovery right } \\
\text { reflex (min) }\end{array}$ & $\begin{array}{c}\text { Completed } \\
\text { Recovery (min) }\end{array}$ \\
\hline 40 & 4 & 8 & 55 & 320 & 67 \\
\hline 40 & 12 & 10 & 60 & 290 & 58 \\
\hline 40 & 8 & 9 & 50 & 300 & 62 \\
\hline Mean & 8 & 9 & 55 & 303 & 62 \\
\hline 60 & 4 & 5 & 46 & 260 & 72 \\
\hline 60 & 5 & 6 & 47 & 250 & 70 \\
\hline 60 & 5 & 4 & 40 & 280 & 76 \\
\hline Mean & 5 & 5 & 43.5 & 265 & 73 \\
\hline 80 & 4 & 7 & 78 & 290 & 80 \\
\hline 80 & 5 & 6 & 74 & 300 & 70 \\
\hline 80 & 3 & 6 & 76 & 310 & 75 \\
\hline 80 & 4 & 5 & 75 & 320 & 77 \\
\hline Mean & 4 & 6 & 75.75 & 305 & 75.5 \\
\hline
\end{tabular}

We note in Table 3 that when ketamine was injected 40,60 and $80 \mathrm{mg} / \mathrm{kg}$ of body respectively. While we noticed the minimum a loss of the right reflex, deep anesthesia, recovery right reflex and completed recovery was $(8,4,5),(50,40,74),(290,260,290)$ and $(62,70,70)$. 


\section{Discussion}

A safe and effective anesthetic protocol for the care of turtles, and in particular of the Caspian Pond turtles, is really important, and unfortunately, there are not enough studies on the clinical anesthetic effects of drug combinations in these animals. It is important to observe the animal for respiratory and circulatory abnormalities and possible clinical signs of sepsis ${ }^{(1)}$. Drugs eliminated by the kidneys such as ketamine are not justified in reptiles with a renal dysfunction. Samples from faeces, aspirates, tracheal fluids or blood can help in making an accurate pre-anesthetic diagnosis. There have been various studies that have evaluated the efficacy and side effects of different drug combinations, such as ketamine in turtle Podocnemis expanse, ${ }^{(4)}$ ketamine in tortoises Gopherus polyphemus, ${ }^{(6)}$ and ketamine in Snapping turtles Chelydra serpentine ${ }^{(7)}$.

Ketamine hydrochloride is an anesthetic and analgesic drug that has been widely used in both human and veterinary medicine, especially in tortoises, ${ }^{(8)}$ and the appropriate dose of the drug for the anesthetization of these animals. The importance of anesthetic and analgesic drugs for the animal medical cares has previously been described, ${ }^{(1,2)}$ such as the importance of the studies about the efficacy and efficiency of the drugs on the animals. To select the best anesthetic protocol, for any patient, the key elements are efficacy, safety, and reliability. An effective protocol provides for a rapid and smooth anesthesia induction as well as a fast and optimal recovery. Furthermore, the optimal anesthetic agent has a rapid onset of action and is quickly cleared from the bloodstream and central nervous system.

Ketamine hydrochloride is a general anesthetic agent characterized by analgesia ${ }^{(11,6)}$, rapid induction, and limited duration of action. The analgesic action of ketamine is due to its ability to bind the N-methyl-Daspartate subtype of glutamate receptor ${ }^{(16)}$. In snakes, inadequate handling was also reported to induce a fatal myositis $(18,20)$. In our experiments, we demonstrated, for the first time, on the terrapin that the time needed to reach anesthesia [Table 1, 2, 3], using ketamine hydrochloride. We note in Table 1 that when ketamine was injected 40, 60 and $80 \mathrm{mg} / \mathrm{kg}$ of body weight, the minimum onset time for doses was $(15,7,5)$, while the most time was $(17,10,5)$ respectively. While we noticed the minimum a loss of the right reflex, deep anesthesia, recovery right reflex and completed recovery was $(21,12,8),(47,58,76),(87,120,140)$ and $(18,24,64)$. We note in Table 3 that when ketamine was injected 40, 60 and $80 \mathrm{mg} / \mathrm{kg}$ of body weight, the minimum onset time for doses was $(4,4,3)$, while the most time was $(12,5,5)$ respectively. While we noticed the minimum a loss of the right reflex, deep anesthesia, recovery right reflex and completed recovery was $(8,4,5),(50,40,74)$, $(290,260,290)$ and $(62,70,70)$.

Furthermore, the measurements of the recovery time followed the same trend [Table1]. In fact, as summarized in Table 1, the onsets of anesthesia, Loss Right reflex, Deep anesthesia, recovery right reflex, completed recovery were found to be, in animals treated with the ketamine hydrochloride. There was evidence that the measurements of efficacy differed between doses. East African reptiles $40-60 \mathrm{mg} / \mathrm{kg}$ I.M. or S.C. $<50 \mathrm{mg} / \mathrm{kg}$ $\sim$ sedation $>50 \mathrm{mg} / \mathrm{kg} \sim$ anesthesia ${ }^{(11)}$. Monitor lizards $50-100 \mathrm{~m} / \mathrm{kg}$ I.M. Results from these type of studies are increasingly in bodies (except royal python) Snakes $50-75 \mathrm{mg} / \mathrm{kg}$ I.M. Ketamine not sufficient, Chelonians $40-90 \mathrm{mg} / \mathrm{kg}$ I.M. surgical anesthesia ${ }^{(19)}$. Therefore, the best dose is $80 \mathrm{mg} / \mathrm{kg}$ for Caspian terrapin, while for freshwater soft shell tortoise it is $80 \mathrm{mg} / \mathrm{kg}$. As for rat snake, the ketamine dose of $80 \mathrm{mg} / \mathrm{kg}$ of body weight was the best according to the study.

\section{Conclusions}

The Caspian terrapin, freshwater soft shell turtles and rat Snakes are an important species of turtles and reptiles, whose conservation status has not yet been evaluated that still needs to be studied under different point of views and for which an anesthetization protocol has to be fully evaluated. This research has shown that the ketamine is the anesthetic with the fastest onset time and shortest recovery time compared to the doses. These results provide new and important information for the medical treatment of an animal species, which is yet to be sufficiently studied. pertinent due to the effect of climate and environmental changes, currently impacting the worldwide turtle populations.

Conflict of Interests: The authors of this paper declare that he has no financial or personal relationships with individuals or organizations that would unacceptably bias the content of this paper and therefore declare that there is no conflict of interests.

Source of Funding: The authors have no sources of funding, so it is self-funding research. 
Ethical Approve: We declare that the study does not need ethical approval.

\section{References}

1. Heard, Darryl J. Reptile anesthesia. Veterinary clinics of north America: exotic animal practice, 2001, 4.1: 83-117.

2. Thurmon J.C., Tranquilli W.J., Benson G.J. Injectable anesthetics. In: Thurmon J.C., Tranquilli W.J., Benson G.J. (eds.) Lumb and Jones' Veterinary Anesthesia, third edition, Williams and Wilkins, Baltimore,USA, 1996; 210-240.

3. Bigham-Sadegh A. Anesthesia with ketaminexylazine-diazepam and/or ketamine-xylazinemidazolam in central Asian tortoise (Testudo horsfieldii) Online J Pharmacol. 2011;7:35-41.

4. Santos AL, Magalhães LM, de Paula Lima CA, Nascimento LR, Menezes LT, Kaminishi ÁP, et al. Anestesia de tartaruga-da-amazônia Podocnemis expansa (Schweigger, 1812) - Testudines, Podocnemididae, com a associação cetamina e propofol. PUBVET. 2011;5:1-11.

5. MALLEY, Dermod. Reptile anaesthesia and the practising veterinarian. In Practice, 1997, 19.7: 351-368.

6. Al-Hamdani AH, Ebrahim SK, Mohammad FK. Experimental xylazine-ketamine anesthesia in the common carp (Cyprinus carpio) J Wildl Dis. 2010;46:596-8.

7. Green, C. J., et al. Ketamine alone and combined with diazepam or xylazine in laboratory animals: a 10 year experience. Laboratory animals, 1981, 15.2: 163-170.

8. Mosley CA. Review of current reptile anesthetic techniques: The do's and don'ts. Proceedings of the North American Veterinary Conference; Orlando, Florida: Eastern States Veterinary Association. 2006. pp. 1646-8.

9. Iverson JB, McCord WP. Variation in East Asian turtles of the genus Mauremys (Bataguridae: Testudines) J Herpetol. 1994;28:178-87.
10. Cooper, J. E. Ketamine hydrochloride as an anaesthetic for East African reptiles. Veterinary Record, 1974, 95.2: 37-41.

11. Green, C. J., et al. Ketamine alone and combined with diazepam or xylazine in laboratory animals: a 10 year experience. Laboratory animals, 1981, 15.2: 163-170.

12. Bienzle, Dorothee; BOYD, Christie J. Sedative effects of ketamine and midazolam in snapping turtles (Chelydra serpentina). Journal of Zoo and Wildlife Medicine, 1992, 201-204..

13. Boever, W. J.; CAPUTO, F. Tilazol (CI 744) as an anesthetic agent in reptiles. The Journal of Zoo Animal Medicine, 1982, 13.2: 59-61.

14. Whitaker BR, Krum H. Medical management of sea turtles in aquaria. In: Fowler ME, Miller RE, eds. Zoo and wild animal medicine.Current therapy 4. Philadelphia: WB Saunders Co, 1999; 217-231.

15. Bienzle D, Boyd CJ. Sedative effects of ketamine and midazolam in snapping turtles (Chelydra serpentina) J Zoo Wild Med. 1992;23:201-4.

16. Wood, F. E.; CRITCHLEY, K. H.; WOOD, J. R. Anesthesia in the green sea turtle, Chelonia mydas. American journal of veterinary research, 1982, 43.10: 1882.

17. Mosley, C. A. Review of current reptile Anesthetic techniques: the do's and don'ts. In: Proc. NA Vet. Conf. 2006. p. 1646-1648.

18. Malley A.D.Reptile anesthesia and the practicing veterinarian. AVA Spring Meeting, March 29-31, Edinburghy Conference; Orlando, Florida: Eastern States Veterinary Association. 2006. pp. 1646-8.

19. Schildger B.-J., Baumgartner R., Hiifeli W., Rubel A., Isenbiigel E. Narkose und Immobilization bei Reptilien. Tieriirztliche Praxis 1993;21, 361-376.

20. Schumacher, J. Reptiles and amphibians. Lumb and Jones Veterinary Anesthesia, 1996, 3: 671-685 